developed pressure (LVDP), the maximum change rate of left ventricular pressure rise and fall $( \pm \mathrm{dp} / \mathrm{dtmax})$ were recorded. The activity of creatine kinase (CK) in coronary outflow, the activity of malonyldialdehyde (MDA) and superoxide dismutase (SOD) in myocardium were dectected. The percentage of necrotic area were observed.

Results In adult rats, the content of CK $(89.48 \pm 18.72 \mathrm{U} / 1$ vs $115.76 \pm 16.72 \mathrm{U} / \mathrm{l}, \mathrm{p}<0.01)$ and $\mathrm{MDA}(9.53 \pm 3.44 \mathrm{nmol} / \mathrm{mg}$ vs $16.84 \pm 2.29 \mathrm{nmol} / \mathrm{mg}, \mathrm{p}<0.01)$ were significantly less in IPC group than those in $\mathrm{I} / \mathrm{R}$ group. In IPC group, the activity of SOD $(584.7 \pm 122.62 \mathrm{U} / \mathrm{mg}$ vs $429.46 \pm 85.24 \mathrm{U} / \mathrm{mg})$, the recovery rate of the left ventricular function, including CO, LVDP and $\pm \mathrm{dp} / \mathrm{dtmax}$, were much higher than those in I/R group $(78.69 \pm 9.68 \%$ vs $65.10 \pm 8.63 \%, \quad 83.61 \pm 8.46 \%$ vs $67.23 \pm 8.68 \%, 81.68 \pm 8.68 \%$ vs $67.89 \pm 6.89 \%, 89.79 \pm 7.78 \%$ vs $66.79 \pm 8.46 \%, p<0.01)$. And the percentage of necrotic area were lower in adult IPC group than in $\mathrm{I} / \mathrm{R}$ group $(5.25 \pm 4.33$ vs $14.75 \pm 8.02, \mathrm{p}<0.01)$. But there were no significant changes between IPC group and I/R group in elderly rats $(p>0.05)$. However, there were great significant changes between enhanced IPC group and IR group in elderly rats, the content of

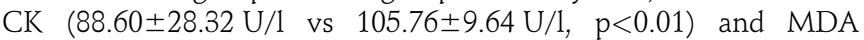
$(8.38 \pm 3.36 \mathrm{nmol} / \mathrm{mg}$ vs $16.80 \pm 3.06 \mathrm{nmol} / \mathrm{mg}, \mathrm{p}<0.05)$, the activity of SOD (558.87 $\pm 78.66 \mathrm{U} / \mathrm{mg}$ vs $433.75 \pm 86.65 \mathrm{U} / \mathrm{mg}, \mathrm{p}<0.01)$, the recovery rate of the left ventricular function, such as CO, LVDP and $\pm \mathrm{dp} / \mathrm{dtmax}$, were much higher than those in $\mathrm{I} / \mathrm{R}$ group $(77.99 \pm 10.02 \%$ vs $66.26 \pm 9.78 \%, 85.59 \pm 6.67 \%$ vs $73.90 \pm 6.66 \%$, $83.87 \pm 9.98 \%$ vs $68.90 \pm 8.68 \%, \quad 86.01 \pm 7.66 \%$ vs $70.39 \pm 7.98 \%$, $\mathrm{p}<0.01)$. The percentage of necrotic area were lower in elderly IPC group than in I/R group $(7.95 \pm 6.32 \%$ vs $15.68 \pm 10.36 \%, p<0.01)$.

Conclusion The effect of IPC on ischaemic reperfused myocardium of elderly rats was weaken. Prolonged ischaemia was able to resume the protective effect of IPC on elderly rat hearts.

\section{e0016 TONGXINLUO REDUCES MYOCARDIAL ISCHAEMIA- REPERFUSION INJURY AND NO-REFLOW BY STIMULATING THE EXPRESSION AND PHOSPHORYLATION OF ENOS VIA PKA PATHWAY}

doi:10.1136/hrt.2010.208967.16

\begin{abstract}
${ }^{1}$ Xiangdong Li, ${ }^{1}$ Yuejin Yang, ${ }^{2}$ Yong-Jian Geng, ${ }^{1}$ Chen Jin, ${ }^{1}$ Feng-Huan $\mathrm{Hu}$, ${ }^{1}$ Jing- Lin Zhao, ${ }^{1}$ Hai-Tao Zhang, ${ }^{3} Y_{u}$-Tong Cheng, ${ }^{1}$ Hai-Yan Oian, ${ }^{1}$ Lin-Lin Wang, ${ }^{1}$ Bao- Jie Zhang, ${ }^{4} Y_{i}$-Ling Wu. ${ }^{1}$ Fuwai Hospital And Cardiovascular Institute; ${ }^{2}$ The University of Texas Houston Medical School; ${ }^{3}$ Beijing An Zhen Hospital; ${ }^{4}$ The Integration of Traditional And Western Medical Research Academy of Hebei Province
\end{abstract}

Objective To investigate whether oral administration of Tongxinluo (TXL), a traditional Chinese medicine, at a single low loading dose $1 \mathrm{~h}$ before myocardial ischaemia can attenuate ischaemia-reperfusion injury by regulating endothelial nitric oxide synthase (eNOS) via protein kinase $\mathrm{A}$ (PKA) pathway.

Methods and results In 90-min ischaemia and 3-h reperfusion model, Minipigs were randomly assigned to four groups $(n=8$ in each group): (1) Sham; (2) Control; (3) TXL: $0.05 \mathrm{~g} \cdot \mathrm{kg}^{-1}$ of TXL was gavaged $1 \mathrm{~h}$ prior myocardial ischaemia; (4) TXL $+\mathrm{H}-89$ $\left(1.0 \mu \mathrm{g} \cdot \mathrm{kg}^{-1} \cdot \mathrm{min}^{-1}\right.$, an inhibitor of PKA). TXL significantly decreased creatine kinase (CK) activity, reduced the infarct size from $78.5 \%$ to $59.2 \%$ and no-reflow area from $48.6 \%$ to $9.5 \%(\mathrm{p}<0.05)$, while $\mathrm{H}-89$ completely abolished the reduction of CK activity and necrosis size, and partially diminished the reduction of no-reflow size. TXL enhanced the PKA activity in ischaemic myocardium, increased the expression of PKA, Thr 198 p-PKA and Ser 635 p-eNOS in no-reflow area, and upregulated the expression of eNOS and Ser 1179 p-eNOS in reflow area. $\mathrm{H}-89$ repressed the enhancement of PKA activity and the upregulation of eNOS and Ser 635 p-eNOS, but without great inhibition on the expression of PKA and Thr 198 p-PKA in no-reflow area, and even stimulated the expression of Ser 635 p-eNOS in reflow area.
Conclusion Pretreatment with single low loading dose of TXL $1 \mathrm{~h}$ before myocardial ischaemia reduces myocardial no-reflow and ischaemia-reperfusion injury by upregulating the expression of eNOS and p-eNOS (Ser 1179 and Ser 635), and this effect is partially mediated by PKA pathway.

\section{e0017 EFFECTS OF EXTRACORPOREAL CARDIAC SHOCK WAVE THERAPY ON ANGIOGENESIS AND EXPRESSION OF VEGF IN ACUTE MYOCARDIAL INFRACTION PIGS}

doi:10.1136/hrt.2010.208967.17

${ }^{1}$ Siming Tao, ${ }^{2}$ Tao Guo, ${ }^{2}$ Yu Wang, ${ }^{2}$ Hongyuan Cai, ${ }^{2}$ Chao Yang. ${ }^{1}$ The No.2 Peoples' Hospital of Yunnan Province; ${ }^{2}$ The No.1 Hospital Affiliated To Kunming Medical College

Objective To investigate the effect of different methods of extracorporeal cardiac shock wave therapy on angiogenesis and expression of VEGF in acute myocardial infraction pigs, and optimise that of methodology.

Methods 25 miniature swine were randomly divided into three groups: group of cardiac shock wave therapy $(n=15)$, positive control group $(n=5)$, negative control group $(n=5)$. According to the method, the animals of cardiac shock wave therapy were divided three subgroups: standard, prolonged course of treatment and extend area. The number of capillary density, mRNA of VEGF were evaluated and compared between with every group.

Results Compared with control positive group, the number of capillary density $(837 \pm 54$ vs $1856 \pm 78, \mathrm{p}<0.0001)$ and expression mRNA of VEGF $(20.52 \pm 4.94$ vs $28.56 \pm 6.84)$ increased in the group of cardiac shock wave therapy, especially, in group of prolonged course of treatment. Whereas, there was no significance in the difference of between standard group and extend area group in capillary density $\left(1633 \pm 24\right.$ vs $\left.1695 \pm 32 / \mathrm{mm}^{2}, \mathrm{p}>0.05\right)$ and mRNA of VEGF (26.31 \pm 7.24 vs $27.44 \pm 3.59$, p $>0.05$ ).

Conclusions Successive extracorporeal cardiac shock wave therapy at early stage of acute myocardial infarction could improve myocardial micro-vascular circulation. It will be a new and non-invasive angiogenic therapy.

\section{e0018 VAGUS NERVE-MEDIATED ELECTRICAL REMODELLING OF PULMONARY VEINS IN CHRONIC ATRIAL PACING DOGS WITH OR WITHOUT SUPERIOR VENA CAVA AND AORTIC ROOT FAT PAD}

doi:10.1136/hrt.2010.208967.18

Xiong Rixin.

Objectives We aim to elucidate the relationship between vagus nerve and the electrical remodelling of pulmonary veins in vagus nervemediated atrial fibrillation dogs.

Methods 24 adult mongrel dogs weighing 15-20 Kg were randomly divided into sham operation group ( $\mathrm{S}$ group, $\mathrm{n}=8$ ), SVC-Ao fat pad removal group ( $\mathrm{R}$ group, $\mathrm{n}=8$ ) and SVC-Ao fat pad reserved group (Re group, $n=8$ ). After exposure of superior vena cava and aortic root fat pad, SVC-Ao fat pad was excised in R group dogs, and sewed epicardial pacing lead into high right atrium and successively paced for 6 weeks; for Re group dogs, suture of epicardial pacing leads and pace for 6 weeks, take the sham operation dogs as control. To detect the Left Superior Pulmonary Vein, Right Superior Pulmonary Vein, Left Inferior Pulmonary Vein, Right Inferior Pulmonary Vein respectively, including Sinus Cycle Length (SCL), Effective Refractory Period (ERP), dispersion of ERP (dERP), and the expression of $\mathrm{Cx} 40$ and $\mathrm{Cx} 43$ by Western Blot, observed the distribution of gap junctions at pulmonary vein sleeves by immunofluorescence and electron microscope. 